\title{
PENGARUH LINGKUNGAN KERJA DAN PENGEMBANGAN KARIR TERHADAP KINERJA KARYAWAN YANG DIMEDIASI OLEH MOTIVASI KERJA (Studi pada PT. World Innovative Telecommunication Surabaya)
}

\section{The Effect of Work Environment and Career Development on Employee Performance Mediated by Work Motivation (Study at PT. World Innovative Telecommunication Surabaya)}

\author{
Fathur Rozy* \\ Prodi Manajemen Sekolah Tinggi Ilmu Ekonomi Indonesia (STIESIA) Surabaya \\ Jln. Menur Pumpungan 30, Surabaya, 60118, Indonesia \\ Corresponding author e-mail: * fathurrozystiesia@gmail.com
}

\begin{abstract}
Abstrak
Tujuan penelitian ini untuk menganalisa pengaruh lingkungan kerja, pengembangan karir, motivasi kerja memediasi lingkungan kerja, motivasi kerja memediasi pengembangan karir terhadap kinerja karyawan. Obyek penelitian dan populasi dalam penelitian ini adalah karyawan PT. World Innovative Telecommunication Surabaya. Teknik pengambilan sampel jenuh digunakan pada penelitian ini, oleh sebab itu jumlah sampel pada kajian ini yaitu sebanyak 70 orang yang berkerja di PT. World Innovative Telecommunication Surabaya. Teknik analisis data yang digunakan dalam penelitian ini adalah analisis jalur (Path Analysis). Berdasarkan hasil uji asumsi klasik didapatkan bahwa model sudah memenuhi asumsi yang disyaratkan. Hasil uji hipotesis didapatkan bahwa 1) lingkungan kerja berpengaruh signifkan dan positif terhadap kinerja karyawan; 2) pengembangan karir tidak berpengaruh signifikan terhadap kinerja karyawan; 3) motivasi kerja bisa memediasi pengaruh lingkungan kerja terhadap kinerja karyawan; 4) motivasi kerja bisa memediasi pengembangan karir terhadap kinerja karyawan.
\end{abstract}

Kata Kunci : Lingkungan Kerja, Pengembangan Karir, Motivasi Kerja, Kinerja Karyawan.

\begin{abstract}
This study aimed to investigate the effect of work environment, career development, the mediating effect of work motivation to work environment, and the mediating effect of work motivation to career development on employee performance. Its objects and population were employees of PT. World Innovative Telecommunication Surabaya. The study saturated sampling techniques to collect data. The samples were seventy people working in PT. World Innovative Telecommunication Surabaya. The data analysis technique was the path analysis model. The results of the classical assumption test show that the model has fulfilled the assumption. The hypotheticql test resulted that 1) the work environment had a positive and significant effect on employee performance; 2) the career development had a insignificant effect on employee performance; 3) the work motivation could mediate the effect of the work environment on employee performance, and 4) the work motivation mediated career development to employee performance.
\end{abstract}

Keywords: Work Environment, Career Development, Work Motivation, Employee Performance.

Article info:

Submitted: $17^{\text {th }}$ December 2020 Accepted: $21^{\text {st }}$ April 2021

How to cite this article:

F. Rozy, "PENGARUH LINGKUNGAN KERJA DAN PENGEMBANGAN KARIR TERHADAP KINERJA KARYAWAN YANG DIMEDIASI OLEH MOTIVASI KERJA", BAREKENG: J. Il. Mat. \& Ter., vol. 15 no. 2, pp. 267-276, Jun. 2021.

This work is licensed under a Creative Commons Attribution-ShareAlike 4.0 International License Copyright $\odot 2021$ Fathur Rozy 


\section{PENDAHULUAN}

Pada saat ini persaingan bisnis semakin kompetitif dan banyak kompetitor baru yang bermunculan. Salah satu upaya yang dapat dilakukan suatu organisasi dalam mempersiapkan dirinya terhadap perubahan tersebut adalah dengan terus berinovasi dalam pengelolaan sumber daya manusianya. Menurut Mathis dan Jackson [1], sumber daya manusia merupakan salah satu faktor yang penting pada suatu perusahaan untuk mencapai target ataupun cita-cita yang sudah ditetapkan. Mesin, bahan baku, dan aktifitas produksi tidak akan berjalan dengan baik tanpa adanya manusia, dengan demikian sumber daya manusia aset utama bagi perusahaan. Pengelolaan sumber daya manusia pada suatu perusahaan harus perlu diperhatikan dan dimonitoring agar tujuan yang telah ditetapkan oleh perusahaan dapat dicapai.

Setiap perusahaan memiliki tujuannya masing-masing, baik tujuan jangka panjang seperti ekspansi perusahaan, pencapaian laba yang tinggi, eksistensi perusahaan melalui berbagai usaha untuk mendapatkan hati pelanggan, dan lain sebagainya. Banyak upaya yang dilakukan oleh perusahaan untuk menggapai tujuan-tujuan yang telah ditetapkan tersebut. Perusahaan juga memiliki tujuan dari segi kesejahteraan karyawannya yang diatur dalam UU No. 13 tahun 2003 tentang ketenagakerjaan pasal 1 ayat 31 yang berisi tentang kesejahteraan karyawan. Tujuan lain yang ingin dicapai oleh perusahaan yaitu ingin memberikan jasa atau barang yang dibutuhkan oleh konsumen. Perusahaan akan melakukan segala upaya agar konsumen merasa terpuaskan.

Salah satu upaya untuk memuaskan kebutuhan konsumen perusahaan harus meningkatkan kinerja Karyawannya. Ouput perusahaan tergantung dari kinerja dari perusahaan terkait. Hubungan kinerja karyawan yaitu positif, artinya apabila kinerjanya baik maka output yang diperoleh akan bagus. Begitu juga sebaliknya, apabila kinerjanya buruk maka ouput yang diperoleh akan tidak bagus. Monitoring kinerja karyawan perlu diperhatikan supaya output tetap terjamin mutunya. Output yang tidak sesuai harapan konsumen, dapat menyebabkan kekecewaan para konsumen. Risiko terburuknya yaitu konsumen akan pindah ke produsen kompetitor. Apabila banyak konsumen yang pergi, dampaknya adalah penurunan penjualan barang atau jasa. Dampak terburuknya yaitu perusahaan akan mengalami kebangkrutan. Disisi lain, apabila perusahaan mampu menjaga bahkan meningkatkan kepuasan konsumen maka keuntungan yang didapat perusahaan akan meningkat.

PT. World Innovative Telecommunication adalah sebuah merek internasional terdaftar yang berpengalaman mengantarkan produk-produk berkualitas tinggi ke pelanggan di Amerika, Eropa, dan Asia. Dalam pengembangan produk OPPO di Asia khususnya di Indonesia terus dilakukan secara intensif dan terarah untuk menghadapi persaingan pasar yang semakin hari semakin banyak kompetitor yang kompetitif, dengan mengutamakan pengembangan melalui peningkatan pengetahuan dan ketrampilan Sumber Daya Manusia dengan perkembangan Ilmu Pengetahuan dan Teknologi (IPTEK), di harapkan PT. World Innovative Telecommunication dapat berkembang dengan pesat serta mampu bersaing di pasar global dan menguasai pasar smartphone di Indonesia.

Akan tetapi, untuk meningkatkan kinerja karyawan PT. World Innovative Telecommunication masih terdapat beberapa masalah sehingga membuat tujuan tidak tercapai. Karena ketidak stabilan penjualan, perusahaan sulit untuk menguasai pasar Indonesia, sehingga ada konsumen yang beralih kepada produk dari perusahaan lain yang sejenis. Oleh sebab itu pimpinan perusahaan harus mencari strategi lainnya supaya untuk meningkatkan kinerja karyawan. Rivai [2] mengatakan bahwa pengertian kinerja karyawan adalah kontribusi yang diberikan oleh karyawan terhadap perusahaan yang menaunginya. Setiap perusahaan memiliki caranya sendiri untuk meningkatkan kinerja karyawan. Perusahaan harus memperhatikan faktorfaktor yang dapat mempengaruhinya.

Menurut data yang diperoleh langsung dari PT. World Innovative Telecommunication, penjualan di tahun 2017 dan 2019 hanya mampu menjual produk sebanyak 21.098 unit ditahun 2017 dan 23.145 unit tahun 2019, dimana sebelumnya penjualan perusahaan di tahun 2016 sebanyak 23.314 unit produk dan pada tahun berikutnya penjualan di tahun 2018 sebanyak 25.771 unit. Penjualan produk Smartphone OPPO terhadap target penjualan yang ditentukan mengalami fluktuatif dari tahun 2016 sampai tahun 2019. Kondisi ini mengakibatkan tidak tercapainya tujuan perusahaan untuk menguasai pasar di wilayah penjualan yang sudah ditentukan. Oleh sebab itu perlu dilakukan penelitian agar kondisi tersebut tidak berlarut-larut dan menghambat tujuan organisasi dalam menguasai pasar. Hal tersebut menunjukan bahwa penjualan dipengaruhi oleh beberapa faktor. Salah satunya adalah tingkat kinerja karyawan dalam melakukan penjualan. Selain strategi marketing yang sudah diterapkan oleh perusahaan, kinerja karyawan dalam melakukan penjualan merupakan ujung tombak dalam pemenuhan target penjualan yang ditetapkan 
oleh perusahaan. Kinerja karyawan dipengaruhi oleh dari segi internal karyawan maupun eksternal karyawan [1].

Merujuk dari permasalahan di atas, maka dalam meningkatkan kinerja karyawan sesuai dengan pendapat para ahli dan disesuaikan dengan kondisi PT. World Innovative Telecommunication, diprioritaskan penelitian terhadap beberapa variabel yang mempengaruhi kinerja karyawan dalam melakukan penjualan produk, yaitu: motivasi, pengembangan karir yang merupakan salah satu dukungan organisasi, dan keberadaan pekerjaan yang dilakukan karyawan yang merupakan lingkungan kerja karyawan dalam bekerja.

Salah satu yang mempengaruhi kinerja karyawan adalah lingkungan kerja. Fasilitas yang tidak sesuai akan berdampak buruk pada kinerja karyawan. Apabila fasilitas yang diberikan perusahaan bagus maka akan meningkatkan kinerja karyawan. Lingkungan kerja merupakan unsur yang ada disekililing karyawan, baik benda maupun rekan kerja. Perlu pengaturan sedemikian rupa fasilitas yang digunakan agar lingkunagn kerja menjadi nyaman. Peraturan perusahaan yang dibuat harus mendukung kondisi lingkungan menjadi nyaman. Penelitian Eka et al. [3] menghasilkan bahwa lingkungan kerja berpengaruh signifikan dan memiliki pengaruh positif terhadap kinerja karyawan. Berbeda dengan Veronica [4] yang menyatakan bahwa lingkungan kerja tidak berpengaruh signifikan terhadap kinerja karyawan.

Pengembangan karir merupakan variabel lainnya yang dapat mempengaruhi kinerja karyawan. Salah satu target individu karyawan adalah karir yang tinggi. Perlu dibuatkan pelatihan dan workshop untuk meningkatkan kemampuan supaya karir karyawan bisa lebih bagus lagi. Penelitian yang dilakukan oleh Dewi dan Utama [5] bahwa pengembangan karir berpengaruh signifikan dan memiliki pengaruh positif terhadap kinerja karyawan. Berbeda dengan hasil penelitian Deiby et al., [6] yang menunjukkan bahwa pengembangan karir tidak berpengaruh signifikan terhadap kinerja karyawan.

Faktor lainnya yang dapat mempengaruhi kinerja adalah motivasi kerja. Motivasi dapat diartikan sebagai faktor pendorong seseorang melakukan sesuatu. Motivasi yang tinggi akan meningkatkan kinerja karyawan. Penelitian Gunawan et al., [7] menyatakan bahwa motivasi berpengaruh signifikan dan memiliki pengaruh positif terhadap kinerja karyawan. Motivasi kerja sebagai variabel mediasi antara lingkungan kerja terhadap kinerja karyawan dan sebagai variabel mediasi antara pengembangan karir terhadap kinerja karyawan. Penelitian yang dilakukan oleh Destia [8] yang menyatakan bahwa motivasi berpengaruh signifikan sebagai mediasi lingkungan kerja terhadap kinerja karyawan. Lain hasilnya dengan pendapat dari Samtono [9] yang berpendapat bahwa motivasi tidak berpengaruh signifikan sebagai variabel memediasi lingkungan kerja terhadap kinerja karyawan. Sari dan Sriathi [10] menyatakan bahwa motivasi berpengaruh signifikan sebagai variabel yang memediasi pengembangan karir terhadap kinerja karyawan. Sedangkan dalam penelitian Rusli et al., [11] menunjukkan hasil bahwa motivasi tidak berpengaruh sebagai variabel yang memediasi hubungan antara pengembangan karir terhadap kinerja karyawan.

Berdasarkan dari permasalahan yang terjadi dan gap penelitian yang telah dipaparkan, maka perlu dilakukan penelitian dengan tujuan untuk menganalisa pengaruh lingkungan kerja terhadap kinerja karyawan PT. World Innovative Telecommunication Surabaya, pengaruh pengembangan karir terhadap kinerja karyawan PT. World Innovative Telecommunication Surabaya, pengaruh motivasi kerja memediasi lingkungan kerja terhadap kinerja karyawan PT. World Innovative Telecommunication Surabaya, dan pengaruh motivasi kerja memediasi pengembangan karir terhadap kinerja karyawan PT. World Innovative Telecommunication Surabaya.

\section{METODE PENELITIAN}

\subsection{Sumber Data}

Data dalam penelitian ini bersumber dari data karyawan PT World Innovative Telecommunication Surabaya yang berjumlah 85 orang. Adapun kriteria dari responden yang digunakan dalam penelitian ini yaitu:

1) Sampel dengan masa kerja lebih dari 3 bulan, dimaksudkan agar para responden dapat memahami pernyataan-pernyataan instrumen penelitian dalam skala dengan baik.

2) Sampel dengan usia diatas 20 tahun dimaksudkan agar para responden memeberikan pendapat dalam hal keputusan. 
Berdasarkan kriteria di atas maka didapat jumlah populasi sebesar 70 orang yang dijadikan sampel.

\subsection{Variabel Penelitian}

Ada tiga variabel pada penelitian yaitu variabel independen, variabel mediasi, dan variabel dependen. Berikut definisi dari variabel yang digunakan pada penelitian:

1) Lingkungan kerja adalah benda ataupun rekan kerja yang ada disekitar tempat kerja. Menurut Sedarmayanti (2012:46) adapun item - item pernyataan yang digunakan yaitu suasana kerja (LK1), hubungan dengan rekan kerja (LK2), tersedianya fasilitas kerja (LK3), penerangan atau cahaya (LK4), sirkulasi udara (LK5), kebisingan (LK6), dan keamanan kerja (LK7). Lingkungan kerja merupakan variabel independen pada penelitian ini. Simbol dari variabel lingkungan kerja yaitu LK.

2) Pengembangan karir adalah sesuatu yang dapat membuat seseorang bisa lebih bagus dari segi kemampuan, karir, maupun finansial. Menurut Rivai (2013:278). Adapun item - item pernyataan pengembangan karir yaitu prestasi kerja (PK1), exposure (PK2), kesetiaan organisasional (PK3), mentor (PK4), sponsor kesempatan - kesempatan untuk tumbuh (PK5), dan dukungan manajemen (PK6). Pengembangan karir merupakan variabel independen pada penelitian ini. Simbol dari variabel lingkungan kerja yaitu PK.

3) Motivasi kerja adalah suatu rasa yang beringinan untuk menjadi lebih baik lagi dalam bekerja. Adapun item - item pernyataan motivasi dalam penelitian ini mengacu pada teori yang dikemukakan Teori Hierarki Maslow (dalam Mangkunegara, 2011:101) yaitu kebutuhan fisiologis (MK1), keamanan (MK2), social (MK3), penghargaan (MK4), dan akualisasi diri (MK5). Motivasi kerja merupakan variabel mediasi pada penelitian ini. Simbol dari variabel motivasi kerja yaitu MK.

4) Kinerja karyawan adalah ukuran dari suatu output yang telah ditentukan ataupun disepakati sebelumnya. Adapun item - item pernyataan kinerja karyawan menurut Mangkunegara (2013:75) yaitu kualitas kerja (KK1), kuantitas kerja (KK2), tanggung jawab (KK3), kerjasama (KK4), dan inisiatif (KK5). Kinerja karyawan merupakan variabel dependen pada penelitian ini. Simbol dari variabel Kinerja karyawan yaitu KK.

\subsection{Langkah Analisis Penelitian}

Langkah-langkah analisis yang dilakukan dalam penelitian ini adalah sebagai berikut:

1) Melakukan uji validitas dan reliabilitas variabel penelitian. Dikatakan valid apabila nilai koefisien korelasinya lebih besar dari nilai korelasi tabel. Variabel dikatakan reliabel apabila nilai Cronbach Alpha $>0,6$.

2) Melakukan analisis regresi linier berganda.

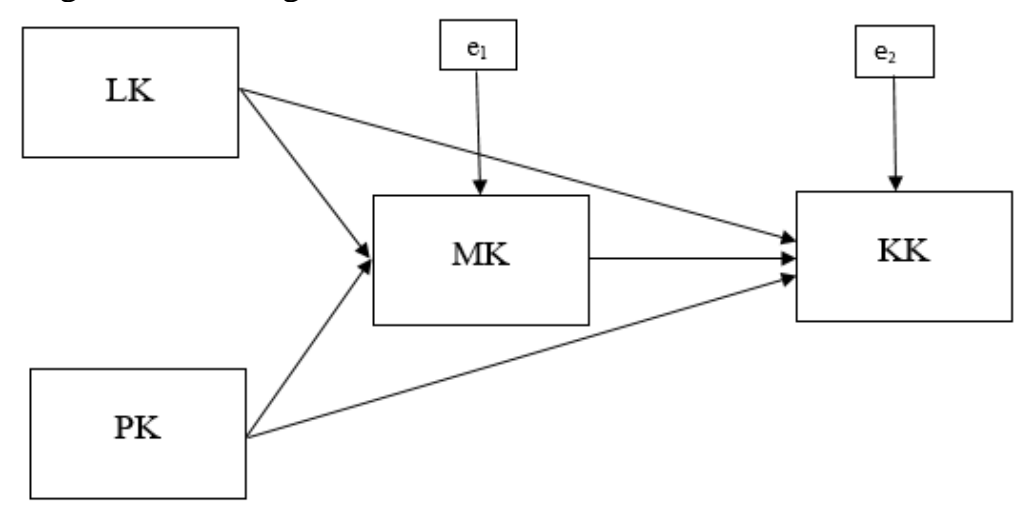

Gambar 1. Diagram jalur

Berikut merupakan model regresi berdasarkan Gambar 1:

$$
\begin{gathered}
\mathrm{MK}=\alpha_{1}+\beta_{1} \mathrm{LK}+\beta_{2} \mathrm{PK}+\mathrm{e} 1 \\
\mathrm{KK}=\alpha_{2}+\beta_{3} \mathrm{LK}+\beta_{4} \mathrm{PK}+\beta_{5} \mathrm{MK}+\mathrm{e} 2,
\end{gathered}
$$

dengan:

$\alpha_{1}=$ konstanta model 1

$\beta_{1}=$ koefisien dari LK untuk model 1

$\beta_{2}=$ koefiesien dari PK untuk model 1 
e1 $=$ error model 1

$\alpha_{2}=$ konstanta model 2

$\beta_{3}=$ koefisien dari LK untuk model 2

$\beta_{4}=$ koefiesien dari PK untuk model 2

$\beta_{5}=$ koefiesien dari MK untuk model 2

$\mathrm{e} 2=$ error model 2

3) Melakukan uji t untuk mengetahui pengaruh dari variabel independen terhadap dependen. Variabel independen dikatakan berpengaruh signifikan terhadap variabel dependen apabila nilai sig. kurang dari 0,05 .

4) Melakukan uji multikolinieritas. Syarat dari bebas multikolinieritas yaitu VIF kurang dari 10.

5) Melakukan uji Kolmogorov Smirnov untuk error dari model regresi. Error dikatakan berdistribusi normal apabila nilai signifikansinya kurang dari 0,05 [12].

6) Melakukan uji autokorelasi menggunakan uji Durbin Watson. Apabila nilai Du < Nilai Durbin Watson $<4-\mathrm{Du}$, maka dikatakan bebas dari kasus autokorelasi. Dimana dU merupakan nilai batas atas pada tabel uji Durbin Watson [13].

7) Melakukan uji heteroskedastisitas menggunakan scatter plot. Apabila pola scatter plot yang terbentuk membentuk pola corong maka terjadi kasus heteroskedastisitas.

8) Melakukan uji sobel untuk mengetahui pengaruh dari variabel mediasi. Dikatakan berpengaruh apabila nilai two-tailed probability kurang dari 0,05 .

9) Mengintepretasikan diagram jalur yang terbentuk.

\section{HASIL DAN PEMBAHASAN}

Pada bagian ini dibahas mengenai analisa dari penelitian. Pertama-tama yaitu melakukan uji validitas dan reliabilitas. Untuk menjawab tujuan dari penelitian dilakukan analisa regresi dari dua model pada persamaan (1) dan (2). Setelah didapatkan model regresi yang sesuai selanjutnya dilakukan pengujian pengaruh dari variabel mediasi menggunakan uji sobel. Langkah terakhir yaitu membuat diagram jalur.

\subsection{Uji validatas dan Reliabilitas}

Untuk mengetahui apakah item-item pernyataan yang digunakan di dalam penelitian ini merupakan penyusun dari variabel, maka dilakukan uji validitas dan reliabilitas. Berikut adalah hasil uji validitas untuk semua variabel penelitian:

Tabel 1. Uji validitas

\begin{tabular}{cccc}
\hline Variabel & Indikator & Koefisien Korelasi & rtabel \\
\hline \multirow{4}{*}{ Lingkungan Kerja (LK) } & $\mathrm{LK}_{1}$ & 0,847 & 0,235 \\
\cline { 2 - 4 } & $\mathrm{LK}_{2}$ & 0,841 & 0,235 \\
\cline { 2 - 4 } & $\mathrm{LK}_{3}$ & 0,855 & 0,235 \\
\cline { 2 - 4 } & $\mathrm{LK}_{4}$ & 0,846 & 0,235 \\
\cline { 2 - 4 } & $\mathrm{LK}_{5}$ & 0,661 & 0,235 \\
\cline { 2 - 4 } & $\mathrm{LK}_{6}$ & 0,858 & 0,235 \\
\hline \multirow{5}{*}{ Pengembangan Karir (PK) } & $\mathrm{LK}_{7}$ & 0,841 & 0,235 \\
\cline { 2 - 4 } & $\mathrm{PK}_{1}$ & 0,958 & 0,235 \\
\cline { 2 - 4 } & $\mathrm{PK}_{2}$ & 0,839 & 0,235 \\
\cline { 2 - 4 } & $\mathrm{PK}_{3}$ & 0,964 & 0,235 \\
\cline { 2 - 4 } & $\mathrm{PK}_{4}$ & 0,957 & 0,235 \\
\cline { 2 - 4 } & $\mathrm{PK}_{5}$ & 0,840 & 0,235 \\
\hline \multirow{5}{*}{ Motivasi Kerja (MK) } & $\mathrm{PK}_{6}$ & 0,937 & 0,235 \\
\cline { 2 - 4 } & $\mathrm{MK}_{1}$ & 0,943 & 0,235 \\
\cline { 2 - 4 } & $\mathrm{MK}_{2}$ & 0,942 & 0,235 \\
\cline { 2 - 4 } & $\mathrm{MK}_{3}$ & 0,898 & 0,235 \\
\cline { 2 - 4 } Kinerja Karyawan (KK) & $\mathrm{MK}_{4}$ & 0,949 & 0,235 \\
\cline { 2 - 4 } & $\mathrm{MK}_{5}$ & 0,941 & 0,235 \\
\cline { 2 - 4 } & $\mathrm{KK}_{1}$ & 0,843 & 0,235 \\
\cline { 2 - 4 } & $\mathrm{KK}_{2}$ & 0,936 & 0,235 \\
\hline & $\mathrm{KK}_{3}$ & 0,917 & 0,235 \\
\hline
\end{tabular}




\begin{tabular}{llll}
\hline $\mathrm{KK}_{4}$ & 0,922 & 0,235 \\
\cline { 2 - 4 } $\mathrm{KK}_{5}$ & 0,921 & 0,235 \\
\hline
\end{tabular}

Berdasarkan uji validitas diperoleh bahwa semua item-item pernyataan (indikator) memiliki nilai koefisien korelasi yang lebih besar dari 0,235. Sehingga dapat disimpilkan bahwa semua variabel sudah valid. Tabel 2 berikut merupakan uji reliabiltas dari variabel penelitian.

Tabel 2. Uji Reliabilitas

\begin{tabular}{lcc}
\hline \multicolumn{1}{c}{ Variabel } & Cronbach Alpha & N of Items \\
\hline Lingkungan Kerja (LK) & 0,914 & 7 \\
\hline Pengembangan Karir (PK) & 0,962 & 6 \\
\hline Motivasi Kerja (MK) & 0,963 & 5 \\
\hline Kinerja Karyawan (KK) & 0,947 & 5 \\
\hline
\end{tabular}

Berdasarkan uji reliabiltas diperoleh bahwa nilai Cronbach Alpha lebih dari 0,6. Sehingga dapat diputuskan semua variabel reliabel. Dari Tabel 1 dan Tabel 2, kita dapat menyimpulkan variabel yang digunakan sudah memenuhi kondisi valid dan reliabel.

\subsection{Analisis Regresi Model 1}

Model regresi 1 ditunjukan oleh persamaan (1). Model tersebut menjelaskan hubungan antara lingkungan kerja dan pengembangan karir terhadap motivasi kerja. Berdasarkan Tabel 3, didapatkan informasi bahwa nilai sig. variabel PK dan LK kurang dari 0,05. Sehingga dapat disimpulkan bahwa variabel PK dan LK berpengaruh signifikan terhadap MK. Nilai VIF dari kedua variabel tersebut yaitu kurang dari 10 sehingga model sudah bebas dari kasus multikolinieritas. Hasil uji Kolmogorov-Smirnov untuk model 1 diperoleh nilai sig. sebesar 0,233, artinya error sudah mengikuti distribusi normal. Untuk nilai Durbin Watson dari model 1 yaitu sebesar 1,814, nilai tersebut 1,680 $<1,814<2,320$. Nilai 1,680 merupakan nilai dU dari tabel Durbin Watson. Sehingga error bebas dari kasus autokorelasi.

Tabel 3. Analsis regresi model 1

\begin{tabular}{lrrccc}
\hline Variabel & Koefisien & Standard error & t & Sig. & VIF \\
\hline Kontanta & 0,629 & 2,266 & 0,278 & 0,782 & \\
\hline PK & 0,434 & 0,082 & 5,317 & 0,000 & 1,102 \\
\hline LK & 0,370 & 0,079 & 4,678 & 0,000 & 1,102 \\
\hline
\end{tabular}

Berikut scatter plot dari model regresi 1:

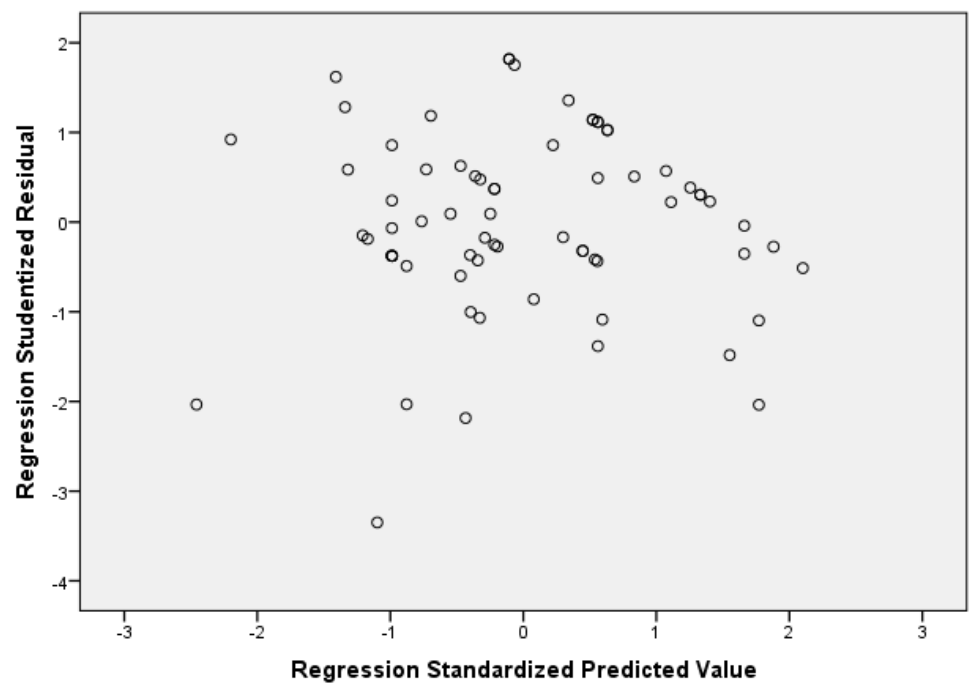

Gambar 1. Scatter plot model regresi 1 
Berdasarkan Gambar 1 dapat dilihat secara visual bahwa scatter plot tidak membentuk pola corong, sehingga dapat dismpulkan bahwa model regresi 1 sudah bebas dari kasus heteroskesdastisitas. Dari model regresi diperoleh nilai $\mathrm{R}^{2}$ sebesar 51,8\%, artinya bahwa variabel independen PK dan LK dapat menjelaskan variabel MK sebesar 51,8\%, sisanya 48,2\% dijelaskan oleh variabel independen lainnya yang tidak ada di model.

\subsection{Analisis Regresi Model 2}

Model regresi 2 ditunjukan oleh persamaan (2). Model tersebut menjelaskan hubungan antara pengembangan karir, lingkungan kerja, dan motivasi kerja terhadap kinerja karyawan.

Tabel 4. Analsis regresi model 2

\begin{tabular}{lccccc}
\hline Variabel & Koefisien & Standard error & T & Sig. & VIF \\
\hline Kontanta & 2,051 & 2,306 & 0,889 & 0,377 & \\
\hline PK & $-0,010$ & 0,099 & $-0,101$ & 0,920 & 1,568 \\
\hline LK & 0,351 & 0,093 & 3,779 & 0,000 & 1,463 \\
\hline MK & 0,432 & 0,124 & 3,474 & 0,001 & 2,075 \\
\hline
\end{tabular}

Berdasarkan Tabel 4, didapatkan informasi bahwa nilai sig. variabel LK dan MK kurang dari 0,05. Dapat dikatakan bahwa variabel LK dan MK berpengaruh signifikan terhadap KK. Untuk nilai sig. dari variabel PK yaitu sebesar 0,920, sehingga dapat disimpulkan bahwa variabel PK tidak berpengaruh terhadap variabel KK. Nilai VIF dari ketiga variabel tersebut yaitu kurang dari 10 sehingga model sudah bebas dari kasus multikolinieritas. Hasil uji Kolmogorov-Smirnov untuk model 2 diperoleh nilai sig. sebesar 0,722, artinya error sudah mengikuti distribusi normal. Untuk nilai Durbin Watson dari model 2 yaitu sebesar 1,903 , nilai tersebut $1,680<1,903<2,320$. Sehingga error bebas dari kasus autokorelasi. Berikut scatter plot dari model regresi 2 :

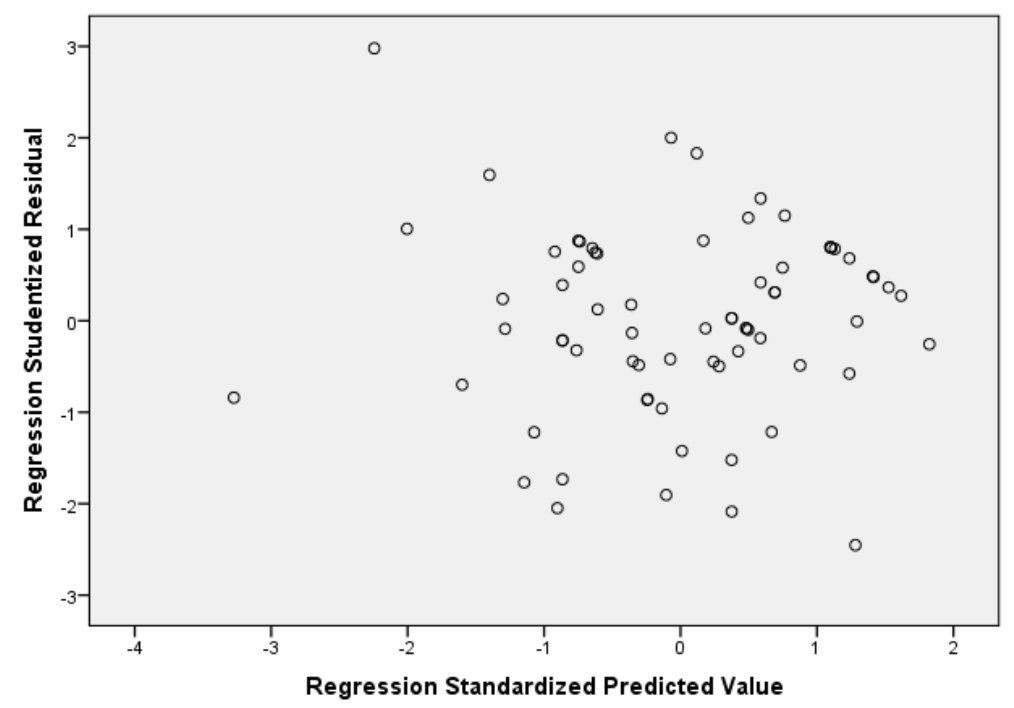

Gambar 2. Scatter plot model regresi 2

Berdasarkan Gambar 2 dapat dilihat secara visual bahwa scatter plot tidak membentuk pola corong, sehingga dapat dismpulkan bahwa model regresi 2 sudah bebas dari kasus heteroskesdastisitas. Dari model regresi diperoleh nilai $\mathrm{R}^{2}$ sebesar 51,6\%, artinya bahwa variabel independen $\mathrm{PK}$, LK, dan MK dapat menjelaskan variabel KK sebesar 51,6\%, sisanya 48,4\% dijelaskan oleh variabel independen lainnya yang tidak ada di model.

\subsection{Uji Sobel}

Untuk mengetahui pengaruh dari variabel mediasi maka dilakukan uji sobel. Untuk melakukan uji sobel digunakan angka pada model regresi 1 dan 2. Angka-angka yang digunakan yaitu nilai koefisien dan 
standar error. Berikut adalah uji sobel untuk pengaruh motivasi kerja memediasi lingkungan kerja terhadap kinerja karyawan.

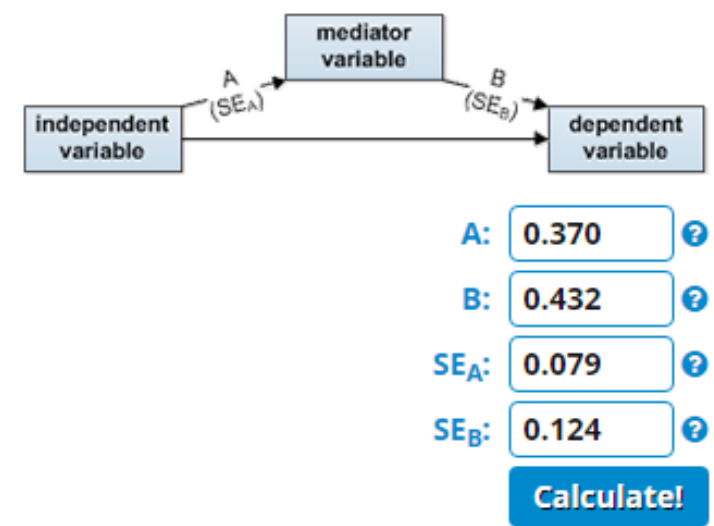

Sobel test statistic: $\mathbf{2 . 7 9 5 3 2 2 1 4}$

One-tailed probability: 0.00259240

Two-tailed probability: 0.00518480

Gambar 3. Uji sobel pengaruh motivasi kerja memediasi lingkungan kerja terhadap kinerja karyawan

Berdasarkan hasil uji sobel pada Gambar 3 dapat diperoleh informasi bahwa variabel motivasi kerja berpengaruh memediasi lingkungan kerja terhadap kinerja karyawan. Berikut adalah uji sobel untuk pengaruh motivasi kerja memediasi pengembangan karir terhadap kinerja karyawan.

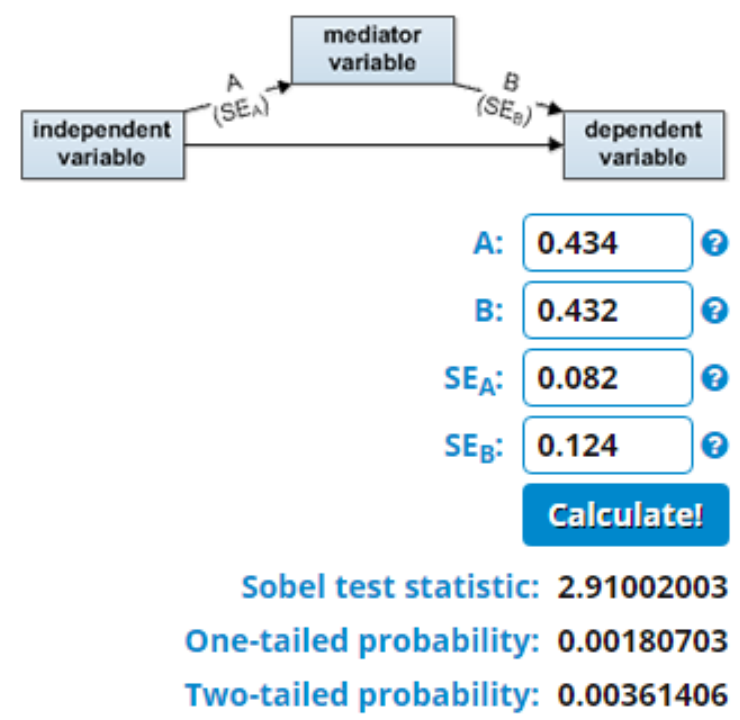

Gambar 4. Uji sobel pengaruh motivasi kerja memediasi pengembangan karir terhadap kinerja karyawan

Berdasarkan hasil uji sobel pada Gambar 4 dapat diperoleh informasi bahwa variabel motivasi kerja berpengaruh memediasi pengembangan karir terhadap kinerja karyawan. 


\subsection{Diagram Jalur}

Berdasarkan hasil analisa yang telah dilakukan berikut disajikan diagram jalur dari penelitian ini:

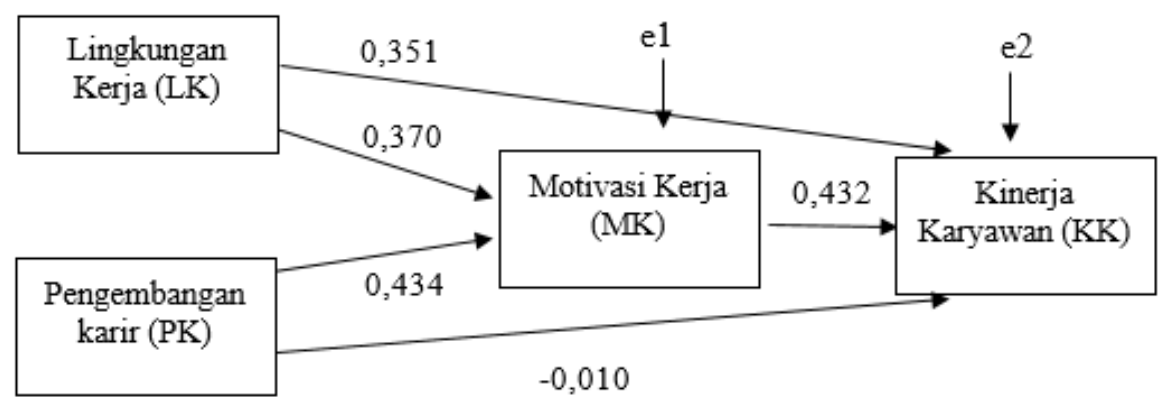

Gambar 5. Diagram jalur dengan koefisien masing-masing variabel

Berdasarkan dari Gambar 5 dan analisa penelitian dapat diketahui bahwa lingkungan kerja berpengaruh signifikan terhadap kinerja karyawan. Hasil ini mendukung dari penelitian Eka et al., [3] yang menyatakan bahwa lingkungan kerja berpengaruh positif dan signifikan terhadap kinerja karyawan. Kedua variabel tersebut memiliki hubungan positif, artinya apabila lingkungan kerja karyawan naik satu satuan maka akan diikuti kenaikan dari kinerja karyawan sebesar 0,351 satuan. Untuk variabel pengembangan karir tidak berpengaruh signifikan terhadap kinerja karyawan. Angka -0,010 tidak memberikan makna yang berarti dari hubungan variabel pengembangan karir dengan kinerja karyawan. Hasil ini mendukung dari hasil penelitian Deiby et al., [6] yang menunjukkan bahwa pengembangan karir tidak berpengaruh signifikan terhadap kinerja karyawan. Motivasi kerja berpengaruh signifikan dalam memediasi lingkungan kerja terhadap kinerja karyawan. Hasil ini mendukung Destia [8] yang menyatakan bahwa motivasi berpengaruh signifikan sebagai mediasi lingkungan kerja terhadap kinerja karyawan. Motivasi kerja berpengaruh signifikan dalam memediasi pengembangan karir terhadap kinerja karyawan. Hasil ini mendukung dari hasil penelitian dari Sari dan Sriathi [10] yang menyatakan bahwa motivasi berpengaruh signifikan sebagai variabel yang memediasi pengembangan karir terhadap kinerja karyawan.

\section{KESIMPULAN}

Berdasarkan hasil analisa dan pembahasan dari penelitian, maka didapat beberapa kesimpulan sebagai berikut ini:

1. Lingkungan kerja berpengaruh signifikan terhadap kinerja karyawan PT. World Innovative Telecommunication Surabaya. Kedua variabel memiliki hubungan positif. Apabila lingkungan kerja mengalami peningkatan maka akan diikuti peningkatan kinerja karyawan. Begitu juga sebaliknya apabila lingkungan kerja mengalami penurunan maka akan diikuti penurunan kinerja karyawan.

2. Pengembangan karir tidak berpengaruh signifikan terhadap kinerja karyawan PT. World Innovative Telecommunication Surabaya.

3. Motivasi kerja berpengaruh signifikan dalam memediasi lingkungan kerja terhadap kinerja karyawan PT. World Innovative Telecommunication Surabaya.

4. Motivasi kerja berpengaruh signifikan dalam memediasi pengembangan karir terhadap kinerja karyawan PT. World Innovative Telecommunication Surabaya.

\section{UCAPAN TERIMA KASIH}

Penulis mengucapkan terimakasih banyak kepada pihak manajemen PT. World Innovative Telecommunication Surabaya atas ijin yang diberikan. Berkat bantuan pihak manajemen, penulis bisa memperoleh data penelitian yang sesuai dengan tujuan dari penelitian ini. 


\section{DAFTAR PUSTAKA}

[1] R. L. Mathis dan J. H. Jackson, Manajemen Sumber Daya Manusia Edisi Pertama Alih Bahasa: Jimmy Sadeli dan Bayu, Jakarta: Salemba Empat, 2012.

[2] Z. V. Rivai, Kepemimpinan dan Perilaku Organisasi Edisi Keempat, Jakarta: Raja Grafindo Persada, 2013.

[3] D. S. Eka dan H. N. Utami, "Pengaruh Lingkungan Kerja Fisik dan Non Fisik Terhadap Kepuasan Kerjadan Kinerja Karyawan (Study Pada Karyawan PT Telkom Indonesia Witel Jatim Selatan Malang)”, Jurnal Administrasi Bisnis, vol. 40, no 1, pp: 56-68. November 2016.

[4] A. D. D. Veronica, "Pengaruh Lingkungan Kerja, Disiplin Kerja dan Komitmen Organisasi terhadap Kinerja Karyawan PT Indomulti Plasindo Di Kota Semarang”, Jurnal Bisnis dan Ekonomi, vol.22, no.1, pp: 17-24, November 2017.

[5] N. L. P. A. A. Dewi dan I. W. M. Utama, "Pengaruh Pengambangan Karir Terhadap Kinerja Karyawan Melalui Mediasi Motivasi Kerja Pada Mas ART Gallery”, Jurnal Manajemen Unud, vol. 9, no.5, pp: 54-62, September 2017.

[6] C. R. Deiby dan R. Torareh, "Pengaruh Disiplin, Motivasi, dan Pengembangan Karir Terhadap Kinerja Pegawai Dinas Pendidikan Kota Manado", Jurnal EMBA, vol.2, no.5; pp:499-510, September 2017.

[7] Y. W. Gunawan dan N. Qomariah, "Pengaruh Moyivasi Kerja, Kompensasi dan Lingkungan Kerja Terhadap Kepuasan Kerja Karyawan (Studi Kasus Pada PT. Sumber Alam Santoso Pratama Karangsari Banyuwangi)”, Jurnal Sains Manajemen dan Bisnis Indonesia", vol. 8, no. 1, pp: 53-67, Juni 2018.

[8] A. Destia, "Pengaruh Karakteristik Individu, Pekerjaan dan Lingkungan Kerja Terhadap Motivasi dan Dampaknya Terhadap Kinerja Anggota Polri di Polresta Palembang”, Jurnal Media Wahana Ekonomika, vol. 12, no.3, pp: 42-54, Oktober 2015.

[9] Samtono, "Pengaruh Lingkungan Kerja dan Kepuasan Kerja terhadap Kinerja Dimediasi Motivasi Kerja pada Guru-guru SMK Ma'arif Comal Pemalang", Jurnal Manajemen, vol 10, no. 20, pp: 95-112, Desember 2017.

[10] N. P. S. K. Sari dan A. A. A. Sriathi, "Peran Motivasi Kerja Memediasi Pengaruh Pengembangan Karir terhadap Kinerja Karyawan Fairmont Sanur Beach Hotel”, E-Jurnal Manajemen, vol.8, no.8, pp: 4788-4814, Agustus 2019.

[11] M. Rusli dan H. M. Ramli, "Pengaruh Pengembangan Karir dan Dukungan Pimpinan terhadap Kinerja Melalui Motivasi Kerja Aparatur Kesyahbandaran dan Otoritas Pelabuhan Parepare”, Journal of Management, vol.1, no.3, pp: 10-16, Oktober 2018.

[12] M. R. Susila, "Pengaruh Hari Raya Idul Fitri Terhadap Inflasi di Indonesia dengan Pendekatan ARIMAX (Variasi Kalender)", Barekeng: Jurnal Ilmu Matematika dan Terapan, vol.14, no.3, pp: 369-378, September 2020.

[13] M. R. Susila, R. C. Putri, dan D. Arini, "Pemodelan Regresi Spasial Investasi Luar Negeri yang Masuk ke Indonesia", Barekeng: Jurnal Ilmu Matematika dan Terapan, vol.14, no.4, pp: 543-556, Desember 2020. 